\title{
Açôes da Comissão Intergestores Regional para gestão compartilhada de serviços especializados no Sistema Único de Saúde ${ }^{1}$
}

I ${ }^{1}$ Roberto Moreira Silveira Filho, ${ }^{2}$ Adriano Maia dos Santos,

${ }^{3}$ Jamille Amorim Carvalho, ${ }^{4}$ Patty Fidelis de Almeida I

Resumo: A fragmentação da assistência e a

dificuldade para ofertar cuidado integral à saúde expõem a necessidade de constituir um território sanitário regional coeso e com cooperação entre municípios. A Comissão Intergestores Regional (CIR), como lócus de governança regional, configura o espaço de pactuação, cooperação e fortalecimento da região de saúde. O artigo objetivou identificar como a regulação da oferta de serviços especializados é abordada nos debates da CIR e quais os principais encaminhamentos. Foi realizado estudo de abordagem qualitativa com base em pesquisa documental a partir da análise das atas e de observações mensais das reuniōes da CIR, constituída por 19 municípios, no período de 2013-2015. Os resultados indicaram que, mesmo com pautas diversificadas, houve foco na atenção especializada/hospitalar. Processos regulatórios restringiram-se à criação de fluxos regionais para atenção hospitalar. Percebeu-se preocupação em relação à permanente revisão do teto financeiro da Programação Pactuada e Integrada (PPI) e dos indicadores do Sistema de Pactuação de Diretrizes, Objetivos, Metas e Indicadores de Saúde (SISPACTO). No caso estudado, a CIR representou um espaço potente para governança regional. As reuniōes revelaram as dificuldades comuns e as estratégias dos gestores para superação dos problemas na oferta e acesso de serviços especializados entre os municípios.

> Palavras-chave: regionalização; acesso aos serviços de saúde; administração de serviços de saúde; atenção secundária à saúde; cobertura de serviços de saúde.

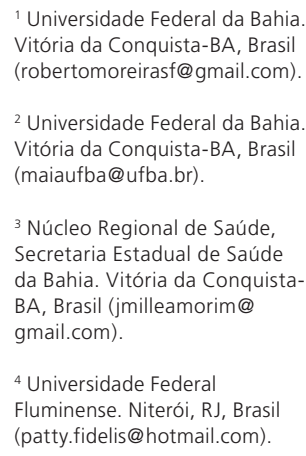

1 Universidade Federal da Bahia. Vitória da Conquista-BA, Brasil (robertomoreirasf@gmail.com).

2 Universidade Federal da Bahia. Vitória da Conquista-BA, Brasil (maiaufba@ufba.br).

${ }^{3}$ Núcleo Regional de Saúde, Secretaria Estadual de Saúde da Bahia. Vitória da ConquistaBA, Brasil (jmilleamorim@ gmail.com)

${ }^{4}$ Universidade Federal Fluminense. Niterói, RJ, Brasil (patty.fidelis@hotmail.com). 


\section{Introdução}

A defesa de um sistema de saúde organizado em redes justifica-se por existir um rompimento na coerência entre a situação de saúde da população, nos quesitos demográficos e epidemiológicos, e as respostas de enfrentamento apresentadas pelos modelos de atenção à saúde, "voltados para atenção às condições agudas e às agudizações de condições crônicas” (MENDES, 2010, p. 2299).

Ainda que reconheça a diversidade de contextos entre os diferentes países e a necessidade de adaptação das propostas às questōes locorregionais, a Organização Pan-Americana de Saúde Pública (OPAS) apontou treze atributos essenciais, ainda que genéricos, ao funcionamento adequado das redes de atenção à saúde: 1) territorialização e adscrição, com amplo conhecimento das necessidades e preferências da população; 2) rede de estabelecimentos de saúde extensa, diversificada (distintas densidades tecnológicas) e integrada, capaz de atender às diferentes demandas sociais de saúde; 3) Atenção Primária à Saúde (APS) atuando como porta de entrada do sistema, composta por equipe multidisciplinar, integrando e coordenando a atenção à saúde e satisfazendo a maior parte das necessidades de saúde; 4) serviços especializados ofertados em local adequado; 5) existência de coordenação dos cuidados longitudinalmente; 6) atenção à saúde centrada na pessoa, família e comunidade, atenta às singularidades e à diversidade da população; 7) sistema de governança único para toda a rede; 8) ampla participação social; 9) gestão integrada dos sistemas de apoio administrativo, clínico e logístico; 10) política de gestão do trabalho em saúde para a rede; 11) sistema de informação integrado e compartilhado; 12) financiamento adequado; e 13) ação intersetorial e equidade (OPAS, 2009).

No Brasil, com as diretrizes do Pacto pela Saúde, nos seus três eixos (Pacto pela Vida, Pacto de Gestão e Pacto em Defesa do SUS), estabeleceram-se novas bases de negociação para o financiamento, definição de responsabilidades, metas sanitárias e compromisso entre as três esferas de gestão do SUS, tendo como diretriz fulcral o processo de regionalização (BRASIL, 2006). Nessa perspectiva, a regionalização tornou-se a diretriz capaz de agregar os atributos necessários à constituição de redes de atenção e superar a fragmentação na provisão de serviços de saúde (SANTOS; CAMPOS, 2015; DUARTE et al., 2015). A regionalização requer distribuiçãao de poder, criação de espaços de discussão entre diferentes entes 
federados e compartilhamento de estratégias de planejamento para integração

de serviços, regulação da assistência, coordenação do cuidado e financiamento interdependente das ações em saúde (SILVA JÚNIOR et al., 2015).

No contexto de manutenção do protagonismo municipal e, simultaneamente, de fortalecimento das relações de interdependência e corresponsabilidade sanitária entre os entes estadual e municipais, foram criadas as Comissões Intergestores Regionais (CIR) (BRASIL, 2011). As CIR são instâncias deliberativas compostas por representantes do estado e todos os secretários municipais de saúde de um determinado território (região de saúde) com capacidade de provisão de serviços de saúde em distintos níveis de atenção. Diferentes estudos têm discutido a institucionalidade, representatividade e dinâmica dos sujeitos que compõem a CIR, além de analisarem os desafios para constituição da governança regional (ASSIS et al., 2009; VIANA; LIMA; FERREIRA, 2010; MEDEIROS, 2013; VIANNA; LIMA, 2013; SANTOS; GIOVANELLA, 2014; SANTOS; ALMEIDA, 2015).

A proposta da CIR é viabilizar, por meio de um planejamento regional integrado, a integralidade de ações e serviços numa região de saúde. Por sua vez, na organização de territórios sanitários e redes regionalizadas de atenção à saúde, estudos apontam que o acesso a serviços de média densidade tecnológica tem sido o principal entrave para garantia de atenção integral (DUBEUX; CARVALHO, 2009; SPEDO; PINTO; TANAKA, 2010; SERRA; RODRIGUES, 2010; SOUZA et al., 2014; ALMEIDA; SANTOS, 2015).

Não obstante, as relações institucionais para construção de uma rede regionalizada de serviços no âmbito do Sistema Único de Saúde (SUS) extrapolam os entes públicos e incorporam uma miríade de arranjos e acordos entre as esferas públicas e privadas (instituiçōes e sujeitos) para provisão de ações e serviços de saúde que não são suficientemente ofertados pela rede própria do SUS e precisam ser complementados. Trata-se de um tema capcioso, mas central, visto que "esse binômio corporifica, no Brasil, impasses histórico-sociais, como a concentração de renda e o predomínio de interesses de grupos e setores econômicos" (HEIMANN et al., 2010, p. 208).

A presença do setor privado de saúde sendo fomentado pelas políticas públicas de saúde no Brasil não é recente (CAMPOS, 2010; BAHIA, 2010), 
mas ganha maior envergadura nos territórios com menor capacidade gestora para exercer a regulação assistencial na relação público-privada, ou em municípios cujos serviços privados e/ou profissionais de saúde tornaram-se aliados das correntes políticas em situação de poder (executivo e/ou legislativo), a ponto de privilegiarem os interesses particulares/privados em detrimento das necessidades sociais e do bem público, numa composição híbrida e patrimonialista (SANTOS; GIOVANELLA, 2014).

Este artigo objetivou identificar como a regulação da oferta de serviços especializados aparece nos debates e quais são as principais deliberações da CIR sobre o tema, analisando-se as estratégias de planejamento e gestão para integração assistencial e acesso oportuno numa região de saúde da Bahia.

\section{Método}

Trata-se de estudo de caso (YIN, 2005) de cunho qualitativo (FLICK, 2009) na região de saúde de Vitória da Conquista, Bahia, envolvendo 19 municípios. De acordo com o Decreto no 7.508 , de 28 de junho de 2011, a região de saúde pode ser definida como um

[...] espaço geográfico contínuo constituído por agrupamentos de municípios limítrofes, delimitado a partir de identidades culturais, econômicas e sociais e de redes de comunicação e infraestrutura de transportes compartilhados, com a finalidade de integrar a organização, o planejamento e a execução de ações e serviços de saúde (BRASIL, 2011).

A regiāo de saúde de Vitória da Conquista tem 637.414 habitantes, representando 4,5\% da população do estado (BAHIA, 2013). Os 19 municípios que compõem a região (quadro 1) podem ser agrupados em quatro estratos por contingente populacional: Estrato 1 - até 10.000 habitantes; Estrato 2 - entre 10.001 a 25.000 habitantes; Estrato 3 - entre 25.001 a 50.000; e Estrato 4 maior que 50.001. A sede da região de saúde é Vitória da Conquista (distante 519 $\mathrm{km}$ de Salvador), o mais populoso município ( $49,5 \%$ da população da região), que, por sua vez, é, também, referência da macrorregião Sudoeste e sede do Núcleo Regional de Saúde do Sudoeste (NRS).

O quadro 1 também apresenta algumas características dos municípios da região de saúde de Vitória da Conquista. As fontes de informação e técnicas de coleta de 
dados foram: documentos oficiais (atas e relatórios técnicos), dados de sistemas de informação e observações em reuniōes da CIR. As observações aconteceram na modalidade "observador não participante", com suporte de um diário de campo (MINAYO, 2010). As atas foram obtidas no sítio do Observatório Baiano de Regionalização, estando disponíveis para o público em geral. O período de observações das reuniōes da CIR deu-se de novembro de 2014, ocasião da $16^{\circ}$ Reunião Ordinária, até julho de 2015, na 21ํ Reunião Ordinária, totalizando sete reuniōes observadas. A pesquisa documental levou em consideração as atas referentes ao período compreendido entre janeiro de 2013 e abril de 2015 (última ata disponível no sítio do Observatório). A escolha dos documentos abrangeu publicaçôes abertas, de acesso público. Os documentos selecionados são oficiais e foram produzidos pela Secretaria Estadual de Saúde (SESAB), pelo Núcleo Regional de Saúde do Sudoeste (NRS) e pela CIR.

Para discussão dos resultados, optou-se pela análise de conteúdo temática (MINAYO, 2010). Para tanto, utilizou-se uma matriz com quatro componentes das redes de atenção à saúde, segundo sistematização da OPAS (2009): 1) Mecanismos regionais de governança; 2) Pontos de atenção secundários; 3) Sistema de apoio diagnóstico e terapêutico; e 4) Sistema logístico (quadro 2).

Para análise, como etapa comum, realizou-se a "ordenação dos dados", um primeiro contato com o material coletado (atas e relatos do diário de campo das observações). No segundo momento, fez-se a "classificação do material" coletado, etapa em que as atas foram lidas exaustivamente, os trechos com as estruturas relevantes e ideias centrais (núcleos de sentido) foram selecionados, agrupados e classificados a partir dos componentes da matriz de análise. Realizou-se o confronto das estruturas relevantes e, em seguida, partiu-se para o cotejamento entre os diferentes dados dos diferentes componentes da matriz. Por fim, os resultados e discussão foram agrupados em duas categorias empíricas: I) Planejamento e regulação de pontos de atenção secundária e serviços de apoio diagnóstico/terapêutico na região de saúde; II) Operacionalização dos sistemas logísticos para continuidade do cuidado na região de saúde.

A pesquisa foi aprovada no Comitê de Ética em Pesquisa, Instituto Multidisciplinar em Saúde, da Universidade Federal da Bahia (Parecer no 624.168), em 24 de abril de 2014. 
Quadro 1. Características de municípios que integram a CIR da região de saúde de Vitória da Conquista, Bahia, 2012.

\begin{tabular}{|c|c|c|c|c|}
\hline \multicolumn{5}{|c|}{ ESTRATO I (ATÉ 10.000 HABITANTES) } \\
\hline Município & $\begin{array}{c}\text { População* } \\
2010\end{array}$ & $\begin{array}{c}\text { Cobertura } \\
\text { ESF** }^{*} 2012\end{array}$ & $\begin{array}{l}\text { IDHM } \\
2010^{* * *}\end{array}$ & $\begin{array}{c}\text { Índice de } \\
\text { Gini 2010*** }\end{array}$ \\
\hline Caraíbas & 9.879 & 100 & 0,555 & 0,49 \\
\hline Cordeiros & 8.245 & 100 & 0,579 & 0,45 \\
\hline Maetinga & 6.048 & 100 & 0,538 & 0,46 \\
\hline Mirante & 9.902 & 100 & 0,527 & 0,52 \\
\hline \multicolumn{5}{|c|}{ ESTRATO II (ENTRE 10.001 A 25.000 HABITANTES) } \\
\hline Anagé & 19.889 & 100 & 0,540 & 0,48 \\
\hline Belo Campo & 17.625 & 100 & 0,575 & 0,49 \\
\hline Bom Jesus da Serra & 10.120 & 100 & 0,546 & 0,52 \\
\hline Caetanos & 14.926 & 100 & 0,542 & 0,50 \\
\hline Condeúba & 17.421 & 100 & 0,582 & 0,49 \\
\hline Encruzilhada & 22.478 & 100 & 0,544 & 0,49 \\
\hline Piripá & 12.219 & 100 & 0,575 & 0,49 \\
\hline Planalto & 24.627 & 98,06 & 0,560 & 0,45 \\
\hline Presidente Jânio Quadros & 12.854 & 100 & 0,542 & 0,53 \\
\hline Ribeirão do Largo & 10.432 & 100 & 0,540 & 0,46 \\
\hline Tremedal & 17.750 & 100 & 0,528 & 0,48 \\
\hline \multicolumn{5}{|c|}{ ESTRATO III (ENTRE 25.001 A 50.000 HABITANTES) } \\
\hline Barra do Choça & 35.501 & 100 & 0,551 & 0,44 \\
\hline Cândido Sales & 25.711 & 100 & 0,601 & 0,50 \\
\hline Poções & 45.903 & 100 & 0,604 & 0,54 \\
\hline \multicolumn{5}{|c|}{ ESTRATO IV (MAIOR QUE 50.000 HABITANTES) } \\
\hline Vitória da Conquista & 315.884 & 42,59 & 0,678 & 0,55 \\
\hline Total & 637.414 & & & \\
\hline
\end{tabular}

Fonte: $\left(^{*}\right)$ Observatório Baiano de Regionalização, (**) Departamento de Atenção Básica da Secretaria de Atenção à Saúde 2015, (***) Atlas do Desenvolvimento Humano no Brasil. 
Quadiro 2. Matriz para análise da rede regional de saúde

\begin{tabular}{|c|c|c|}
\hline Componentes & Núcleos de sentido & $\begin{array}{l}\text { Categorias } \\
\text { empíricas }\end{array}$ \\
\hline \multirow{6}{*}{$\begin{array}{l}\text { Mecanismos } \\
\text { regionais de } \\
\text { governança }\end{array}$} & Funcionamento e regularidade das reuniōes da CIR & \multirow{10}{*}{$\begin{array}{l}\text { Planejamento } \\
\text { e regulação de } \\
\text { pontos de atenção } \\
\text { secundária e } \\
\text { serviços de apoio } \\
\text { diagnóstico/ } \\
\text { terapêutico na } \\
\text { região de saúde }\end{array}$} \\
\hline & $\begin{array}{l}\text { Mecanismo de assessoria da Diretoria Regional de } \\
\text { Saúde para fortalecimento da rede regionalizada }\end{array}$ & \\
\hline & $\begin{array}{l}\text { Existência e funcionamento de Consórcio } \\
\text { Intermunicipal de Saúde }\end{array}$ & \\
\hline & $\begin{array}{l}\text { Forma de aplicação da PPI para oferta de vagas } \\
\text { e existência/tipo de ações que contribuem para } \\
\text { reduzir as lacunas assistenciais }\end{array}$ & \\
\hline & $\begin{array}{l}\text { Influência do setor privado no processo de } \\
\text { regionalização e nos planos regionais }\end{array}$ & \\
\hline & $\begin{array}{l}\text { Existência de acordo entre entes federados por meio } \\
\text { de Contrato Organizativo da Ação Pública (COAP) }\end{array}$ & \\
\hline \multirow{2}{*}{$\begin{array}{l}\text { Pontos de } \\
\text { atenção } \\
\text { secundários }\end{array}$} & Disponibilidade de pontos de atenção secundária & \\
\hline & $\begin{array}{l}\text { Estratégia para oferta, com escala adequada, } \\
\text { entre os pontos de atenção à saúde e os territórios } \\
\text { sanitários }\end{array}$ & \\
\hline \multirow{2}{*}{$\begin{array}{l}\text { Sistema } \\
\text { de apoio } \\
\text { diagnóstico e } \\
\text { terapêutico }\end{array}$} & $\begin{array}{l}\text { Disponibilidade de serviços diagnóstico e } \\
\text { terapêutico }\end{array}$ & \\
\hline & $\begin{array}{l}\text { Estratégia para oferta, com escala adequada, entre } \\
\text { os serviços de apoio e terapêuticos saúde e os } \\
\text { territórios sanitários }\end{array}$ & \\
\hline \multirow[t]{5}{*}{$\begin{array}{l}\text { Sistema } \\
\text { logístico }\end{array}$} & $\begin{array}{l}\text { Cadastramento dos estabelecimentos e profissionais } \\
\text { da região }\end{array}$ & \multirow{5}{*}{$\begin{array}{l}\text { Operacionalização } \\
\text { dos sistemas } \\
\text { logísticos para } \\
\text { continuidade do } \\
\text { cuidado entre } \\
\text { níveis na região de } \\
\text { saúde }\end{array}$} \\
\hline & $\begin{array}{l}\text { Regulação e marcação de consultas e exames } \\
\text { especializados }\end{array}$ & \\
\hline & Regulação e controle de leitos e internações & \\
\hline & $\begin{array}{l}\text { Instrumentos para continuidade do cuidado entre } \\
\text { os níveis de atenção }\end{array}$ & \\
\hline & Transporte sanitário & \\
\hline
\end{tabular}

Fonte: Elaboração própria, baseado em OPAS (2009). 


\section{Planejamento e regulação de pontos de atenção secundária e serviços de apoio diagnóstico/terapêutico na regiāo de saúde}

No quadro 3, pode-se visualizar um panorama das discussões e temáticas da CIR a respeito do planejamento regional em saúde. Os resultados apresentam as açôes empreendidas por gestores na região de saúde para planejamento, implementação e regulação de serviços especializados. Por abarcarem uma problemática comum entre os municípios, o planejamento e a regulação de pontos de atenção secundária e serviços de apoio estiveram presentes, com maior ou menor destaque, em todas as reuniōes da CIR analisadas, seja como informe ou pauta principal.

Quadro 3. Planejamento e regulação de pontos de atenção secundária e serviços de apoio diagnóstico e terapêutico na região de saúde: açōes empreendidas por gestores na região de saúde para planejamento, implementação e regulação de serviços especializados.

\begin{tabular}{|l|l|}
\hline \multicolumn{1}{|c|}{ Núcleo de sentido } & \multicolumn{1}{c|}{ Resultados das atas } \\
\hline $\begin{array}{l}\text { Funcionamento e } \\
\text { regularidade das } \\
\text { reuniōes da CIR }\end{array}$ & $\begin{array}{l}\text { Verificou-se assiduidade dos membros representantes do Estado } \\
\text { às reuniōes; } \\
\text { Frequência dos secretários municipais às reuniōes, garantindo } \\
\text { quórum mínimo, porém com caráter ainda normativo, visto que } \\
\text { apenas nas reuniōes do SISPACTO houve 100\% da presença dos } \\
\text { gestores (n=19); verificou-se presença expressiva (18 gestores) em } \\
\text { outra reunião (04/09/13) que tratou do rateio do Samu 192 com a } \\
\text { região de Itapetinga e contou com a presença de técnicos da SESAB } \\
\text { para discussão do Projeto Olhar Brasil e do Programa TFD; } \\
\text { Convidados (assessores/técnicos das secretarias municipais e da } \\
\text { regional de saúde, representantes de serviços de saúde da região, } \\
\text { estudantes/professores/pesquisadores da área de saúde) estiveram } \\
\text { presentes em número expressivo (maior que o no de membros da } \\
\text { CIR) em 30\% das reuniões; }\end{array}$ \\
\hline $\begin{array}{l}\text { Mecanismo de } \\
\text { assessoria da Diretoria } \\
\text { Regional de Saúde } \\
\text { para fortalecimento } \\
\text { da rede regionalizada }\end{array}$ & $\begin{array}{l}\text { Espaço da CIR ampliou a relação cooperativa entre os entes } \\
\text { municipal e regional, verificada através da participação ativa } \\
\text { de ambos em Grupos de Trabalho para construção dos Planos } \\
\text { das Redes Temáticas; articulaçáo de discussóes temáticas e } \\
\text { capacitações nos principais temas sinalizados pelos gestores } \\
\text { municipais; fomento de reuniōes periódicas entre profissionais } \\
\text { dos municípios e da regional, por área técnica (Atenção Básica, } \\
\text { Assistência Farmacêutica, Vigilância Epidemiológica); }\end{array}$ \\
\hline
\end{tabular}

continua... 


\begin{tabular}{|c|c|}
\hline Núcleo de sentido & Resultados das atas \\
\hline $\begin{array}{l}\text { Existência e } \\
\text { funcionamento } \\
\text { de Consórcio } \\
\text { Intermunicipal de } \\
\text { Saúde }\end{array}$ & $\begin{array}{l}\text { Espaço da CIR possibilitou o compartilhamento dessa experiência } \\
\text { de consórcio como alternativa para ampliação da oferta de serviços } \\
\text { de média complexidade tecnológica com recursos próprios dos dez } \\
\text { municípios consorciados; }\end{array}$ \\
\hline $\begin{array}{l}\text { Forma de aplicação } \\
\text { da PPI para oferta de } \\
\text { vagas e existência/ } \\
\text { tipo de ações que } \\
\text { contribuem para } \\
\text { reduzir as lacunas } \\
\text { assistenciais }\end{array}$ & $\begin{array}{l}\text { A necessidade de adequação da Programação Pactuada e Integrada } \\
\text { (PPI) referente ao planejamento ambulatorial de serviços de } \\
\text { média densidade tecnológica apareceu frequentemente no debate, } \\
\text { sobretudo, na busca de remanejamento de procedimentos alocados } \\
\text { em Vitória da Conquista para outros municípios da região; }\end{array}$ \\
\hline $\begin{array}{l}\text { Influência do setor } \\
\text { privado no processo } \\
\text { de regionalização e } \\
\text { nos planos regionais } \\
\text { das redes temáticas }\end{array}$ & $\begin{array}{l}\text { Gestores municipais aproveitaram a reunião da CIR para sinalizar } \\
\text { que há grupos de empresários (donos de clínicas) assediando } \\
\text { prefeitos, oferecendo serviços e prometendo interferências na } \\
\text { PPI, quando havia posicionamento do Estado em atualizar a } \\
\text { PPI somente com a implementação do COAP no Estado; houve, } \\
\text { também, sinalizações acerca da dificuldade de execução do no de } \\
\text { consultas/procedimentos pactuados baseados nos valores da tabela } \\
\text { SUS (defasada), visto que existe uma imposição de outros valores } \\
\text { pelos prestadores privados para contratualização; nos planos } \\
\text { regionais das redes temáticas esta problemática ainda não pôde } \\
\text { ser diretamente avaliada por encontrar-se em fase de implantação; }\end{array}$ \\
\hline $\begin{array}{l}\text { Existência de acordo } \\
\text { entre entes federados } \\
\text { por meio de Contrato } \\
\text { Organizativo da Ação } \\
\text { Pública (COAP) }\end{array}$ & $\begin{array}{l}\text { Embora tal tema tenha aparecido em uma reunião da CIR, o } \\
\text { pouco avanço na formalização do COAP na Bahia tem colaborado } \\
\text { para descompasso entre as pactuações e as atuais necessidades de } \\
\text { saúde dos municípios. Dessa forma, ainda não foi possível verificar } \\
\text { quais os impactos dessa experiência na região de saúde; }\end{array}$ \\
\hline $\begin{array}{l}\text { Disponibilidade de } \\
\text { pontos de atenção } \\
\text { secundária e de } \\
\text { serviços de apoio } \\
\text { diagnóstico e } \\
\text { terapêutico }\end{array}$ & $\begin{array}{l}\text { Verificou-se que os municípios buscam, também, comprar } \\
\text { diretamente do prestador privado e ofertar serviços no seu próprio } \\
\text { território, mesmo já tendo pactuado; }\end{array}$ \\
\hline
\end{tabular}

continua... 


\section{Núcleo de sentido}

Estratégia para

oferta, com escala

adequada, entre os

pontos de atenção à

saúde, os serviços de

apoio diagnóstico

e terapêutico e os

territórios sanitários

\section{Resultados das atas}

O espaço da CIR teve um papel de interlocutor e moderador das demandas entre municípios: o GT-PPI desenvolveu uma planilha para diagnóstico regional da pactuação atual, bem como para definir qual o fluxo assistencial mais adequado para cada município, de forma a propor realocação de recursos e revisão da PPI pelo Estado; a Assistência Farmacêutica Básica possibilitou o posicionamento regional frente à $\mathrm{CIB} / \mathrm{SESAB}$ quanto à municipalização do recurso federal da Assistência Farmacêutica (que passava por desabastecimento crônico dos itens adquiridos através do Estado); quanto à elaboração dos Planos Regionais das Redes Temáticas, houve definição sobre a localização estratégica de novos serviços no território regional, visando à adequação da população referenciada para cada serviço, distâncias/fluxo de transporte, evitando sobrecarga ou esvaziamento dos serviços.

A atenção secundária à saúde concentra boa parte dos recursos necessários para a oferta integral da assistência à saúde, além de ser estratégica para a resolubilidade (ERDMANN et al., 2013), o que acaba por priorizar essa temática na CIR.

Nas atas, e também em observações nas reuniōes da CIR, percebeu-se a constante presença de profissionais de áreas temáticas específicas (não titulares à CIR), convidados pelos gestores, para qualificar o debate e apoiar os secretários de saúde na tomada de decisão. Tal questão foi evidenciada, também, nos estudos de Santos e Almeida (2015) e Assis e Jesus (2012).

Entre os temas, a necessidade de adequação da Programação Pactuada e Integrada (PPI) referente ao planejamento ambulatorial de serviços de média densidade tecnológica apareceu no debate, sobretudo, na busca de remanejamento de procedimentos alocados em Vitória da Conquista para outros municípios da região. Essa demanda aparece por dois motivos principais: ora porque Vitória da Conquista não conseguia ofertar plenamente a demanda de determinadas especialidades para todos os municípios na quantidade pactuada (por exemplo: raio X, ortopedia, psiquiatria, pediatria), ora porque era mais vantajoso economicamente para determinado município passar a ofertar algumas especialidades em seu próprio território. Problema semelhante à região de saúde do Grande ABC, em São Paulo, onde a condução da PPI sofre alguns entraves, como a resistência de gestores em alterar pactuaçôes, mesmo 
quando necessárias, e em função da capacidade instalada insuficiente frente ao programado (SILVA; GOMES, 2014).

No primeiro caso, segundo gestores, há insuficiência de médicos especialistas que aceitem ser trabalhadores assalariados do SUS, sendo comum o não preenchimento de vagas em seleções e concursos públicos para muitas especialidades. Compreende-se, porém, que não se trata de um mero desejo dos profissionais, visto que as políticas de gestão do trabalho no SUS não têm sido suficientemente atrativas. Outra problemática é que Vitória da Conquista, muitas vezes, não consegue contratar prestadores privados que aceitem ofertar serviços nos valores da tabela SUS. Nesse sentido, para o prestador privado, os valores pagos pela tabela SUS são insuficientes para a garantia de oferta adequada aos usuários (VICTORA et al., 2011). Em contrapartida, o sistema privado de saúde tem sido beneficiado com políticas do governo federal, por meio de renúncia de arrecadação fiscal e outros mecanismos (OCKÉ-REIS, 2010).

Essas questôes são sinérgicas, pois, de um lado, a diminuição da oferta pública pressiona a necessidade de compra do setor privado, que, por outro lado, tem sua demanda aumentada e, portanto, eleva os valores dos procedimentos especializados. Como resultado, para ofertar os serviços, os municípios pactuam com Vitória da Conquista, que também compra os serviços com valores mais elevados que os pactuados e, assim, oferta uma quantidade menor para compensar os valores inflacionados pelo mercado, gerando insatisfação em todas as direções. Tal situação vai ao encontro de achados na região de saúde do Grande ABC, onde os pactos não são cumpridos "seja porque os municípios não oferecem os serviços, seja porque não se encontram os profissionais para fazer o atendimento" (SILVA; GOMES, 2014, p. 1393).

No segundo caso, para driblar a oferta menor em Vitória da Conquista, os municípios buscavam, também, comprar serviços diretamente do prestador privado e ofertá-los no seu próprio território, mesmo já tendo pactuado regionalmente. Nesse caso, a justificativa assentava-se na diminuição dos gastos com transporte sanitário e alimentação dos usuários, maior autonomia sobre as agendas de marcação de consultas, maior proximidade geográfica do serviço para o usuário (evitando as frequentes ausências das pessoas aos serviços de especialidades) e, por fim, na redução no tempo de espera.

Destaca-se que Vitória da Conquista era o maior provedor de serviços regionais, e apenas mais quatro municípios na região (Barra do Choça, Belo 
Campo, Maetinga e Presidente Jânio Quadros) assumiram o Comando Único, ou seja, os demais não recebiam o recurso diretamente em seu Fundo Municipal de Saúde (FMS) para definir a contratação de serviços especializados no seu próprio território, necessitando de intermediação financeira da Secretaria de Saúde do Estado. Ressalta-se, porém, que, apesar da autonomia dos municípios com comando único na contratação de prestadores, na perspectiva da regionalização, “o comando único (ou direção única) em cada nível de governo não deve, todavia, prescindir da ação integrada entre os gestores do sistema nos três níveis de governo" (GAWRYSZEWSKI; OLIVEIRA; GOMES, 2012, p.132). Nesse sentido, municípios que não assumiram o comando único usavam recurso próprio do tesouro (contrapartida municipal) para minimizar os entraves na oferta de especialidades, todavia comprometendo seus parcos recursos, afetando, inclusive, as ações na atenção primária à saúde.

Além disso, o pouco avanço na formalização do Contrato Organizativo da Ação Pública da Saúde (COAP), segundo ressalta um dos gestores, colaborava para descompasso entre as pactuações e as necessidades de saúde dos municípios, embora tal tema tenha aparecido em apenas uma reunião da CIR. Mendes et al. (2015) constatam, também, que o COAP era pouco mencionado pelos gestores em São Paulo e se apresentava no contexto da captação de recursos financeiro em detrimento de um instrumento de consolidação sanitária.

Ressalta-se que, na Bahia, esse processo é incipiente, visto que não houve implantação do COAP em nenhuma região de saúde do estado. Nesse intervalo de indefinições, os municípios experimentam alternativas como mutirōes (mamografia, catarata) e consórcios intermunicipais, como a Associação dos Municípios da Microrregião do Sudoeste da Bahia (AMIRS), sediada em Poções, e que abrange outros cinco municípios da região de Vitória da Conquista (Barra do Choça, Bom Jesus da Serra, Caetanos, Mirante, Planalto), além de municípios da região de Itapetinga (Caatiba) e Jequié (Boa Nova, Manoel Vitorino e Nova Canaã). Contudo, percebe-se que as alternativas minimizam problemas de maneira pontual e não resolvem os reais nós críticos da rede regional. O modelo de consórcios intermunicipais, por exemplo, em funcionamento no país há décadas, tem regras bem estabelecidas, com o intuito de regular os serviços usufruídos pelos municípios participantes fazendo com que haja uma distribuição equânime dos serviços e um criterioso controle dos seus beneficiários, evitando, dessa 
maneira, o uso por municípios não contribuintes ou inadimplentes. Por outro lado, a rede de serviços contratada por consórcios privilegia determinados tipos de serviços - eletivos, por exemplo - e tem restriçōes quanto à universalidade e a integralidade na oferta dos atendimentos (MACHADO, 2010).

Percebem-se, com os problemas elencados, desafios à consolidação de redes regionais. A dependência do setor privado, a baixa capacidade de oferta pública e a solução encontrada, de ofertar especialidades de maneira pulverizada entre os municípios, por meio de compra direta do prestador, têm diminuído o poder regulatório e aumentado a sobreposição defluxos. Nessa direção, gestores municipais aproveitam a reunião da CIR para sinalizar que há grupos de empresários (donos de clínicas) assediando prefeitos, oferecendo serviços e prometendo interferências na PPI. Em um estudo anterior, na mesma região de saúde, destacou-se como ponto crítico na rede de serviços da região "a ação de atravessadores contratados por secretarias de saúde para agilizar o acesso aos serviços especializados, serviços de apoio diagnóstico e terapêutico e/ou cirúrgico em outros municípios mediante pagamento (taxas e bonificações) direto a médicos por procedimentos já custeados pelo SUS" (SANTOS; GIOVANELLA, 2014, p. 627).

Um avanço na CIR foi a implantação, em 2013, de Grupos de Trabalho (GT) de caráter permanente; entre estes, o GT-PPI, constituído por secretários de saúde e técnicos dos municípios e da regional de saúde, que se reuniu periodicamente para discussão técnica dos principais problemas relacionados às pactuações intermunicipais e proposição de possíveis realocações de recurso. O GT-PPI elaborou uma planilha para diagnóstico regional e levantamento de pactuação "não atendida" ou "atendida de maneira insuficiente", bem como definiu qual o fluxo assistencial mais adequado para cada município, de forma a propor realocação de recurso e revisão da PPI pelo estado.

Constatou-se que os grupos de trabalho apresentavam suas sínteses nas sessões ordinárias da CIR e tal dinâmica qualificava a discussão das reuniões e mantinha o planejamento regional ativo e não limitado aos encontros mensais da CIR, ou seja, sinaliza, inclusive, um avanço em relação ao que foi constatado em pesquisa anterior na mesma região (SANTOS; GIOVANELLA, 2014).

As reuniōes da CIR serviram, também, para compartilhamento do manual do SISPACTO e de metodologia proposta por técnicos da Regional de Saúde para realização da pactuação de indicadores 2014-2015. Essa ação permitiu que os 
municípios compartilhassem seus indicadores e conhecessem as especificidades locorregionais, identificando dificuldades e potencialidades comuns e visualizando prioridades/estratégias para o planejamento em saúde; entretanto, pareceu ser compreendido pelos gestores, ainda, como mais uma ação normativa para atendimento de exigências ministeriais/estaduais do que uma necessidade para fortalecimento regional.

Além disso, em diversas reuniōes da CIR, foi debatido o atraso na elaboração e entrega dos Planos Municipais de Saúde e Relatórios Anuais de Gestão (RAG), comprometendo o planejamento e a avaliação de açôes e serviços no âmbito municipal, via alimentação de dados no SARGSUS. Também havia dados desatualizados em diversos outros sistemas de informação sobre serviços oferecidos e distribuição de profissionais. Tais problemas estiveram relacionados ora à capacidade técnica de alguns gestores na elaboração de documentos avaliativos e de monitoramento, ora à percepção normativa/burocrática que alguns gestores tinham em relação aos instrumentos de gestão. Problemática semelhante foi discutida por Vidor, Fisher e Bordin (2011) em municípios gaúchos de pequeno porte.

Ressalta-se, também, que os municípios da região apresentavam dificuldades para formar quadro de gestores e técnicos qualificados, havendo alta rotatividade de profissionais das secretarias e insuficiência de recursos para qualificação dos processos de gestão; ou seja, em muitos municípios um único profissional precisa responder a inúmeras funçôes administrativas, acarretando sobrecarga de trabalho. Entretanto, nas reuniōes da CIR, houve entre os gestores acordos de cooperação mútua para elaboração de documentos de gestão, para qualificação dos técnicos municipais em relação a determinados sistemas de informação, além do apoio institucional da regional de saúde e técnicos do nível central da SESAB.

\section{Operacionalização dos sistemas logísticos para continuidade do cuidado entre níveis na região de saúde}

Os principais resultados estão sintetizados no quadro 4. Os sistemas logísticos referem-se a um dos componentes de uma rede de atenção à saúde ancorada em tecnologias de informação comunicacional, que garantem organização dos fluxos e contrafluxos, sistema de referência e contrarreferência das pessoas ao longo dos pontos de atenção à saúde e dos sistemas de apoio (MENDES, 2010). 

entre níveis na região de saúde: ações de regulação, informação e transporte (produtos e pessoas) empreendidas pelos gestores para a integração dos serviços.

\begin{tabular}{|l|l|}
\hline \multicolumn{1}{|c|}{ Núcleo de sentido } & \multicolumn{1}{c|}{ Resultados das atas } \\
\hline $\begin{array}{l}\text { Cadastramento dos } \\
\text { estabelecimentos e } \\
\text { profissionais da região }\end{array}$ & $\begin{array}{l}\text { Pautas sobre a importância/necessidade de atualização do } \\
\text { SCNES surgiram especialmente como demanda da Central } \\
\text { de Regulação de Leitos Hospitalares e do GT Rede Cegonha. } \\
\text { Para a Central, era necessário conhecer a capacidade instalada } \\
\text { e a oferta potencial dos leitos em cada território da região } \\
\text { para o planejamento e utilização dos serviços no local mais } \\
\text { apropriado e oportuno. O GT Rede Cegonha necessitava de } \\
\text { informações atualizadas sobre o número de leitos obstétricos } \\
\text { existentes na Região e profissionais disponíveis para melhor } \\
\text { direcionamento dos investimentos em unidades pré-existentes } \\
\text { ou novas. Em ambos os casos, verificavam-se inconsistências } \\
\text { quanto aos serviços/profissionais efetivamente disponíveis nos } \\
\text { hospitais, especialmente na questão obstétrica, visto que muitos } \\
\text { leitos cadastrados não dispunham de profissional médico ou } \\
\text { enfermeiro obstetra de referência para os partos; verificava-se, } \\
\text { ainda, o funcionamento de centros de saúde como pequenos } \\
\text { hospitais (plantóes 24 horas, urgência, sala de parto, pequeno } \\
\text { internamento) sem o devido credenciamento para recebimento } \\
\text { de recursos de custeio estaduais/federais. Em algumas atas, foi } \\
\text { possível perceber que a proposta de custeio dos Hospitais de } \\
\text { Pequeno Porte (HPP) pelo Estado não é atrativa aos municípios } \\
\text { (recurso financeiro). Tal situação leva os municípios a manter } \\
\text { com recursos “próprios" estruturas dispendiosas e que nem } \\
\text { sempre comportam a demanda. }\end{array}$ \\
\hline especializados & $\begin{array}{l}\text { A discussão esteve mais associada ao financiamento e à } \\
\text { desatualização da PPI do que especificamente às centrais de } \\
\text { marcação de consultas ou à regulação dos fluxos; }\end{array}$ \\
\hline
\end{tabular}

continua... 


\begin{tabular}{|c|c|}
\hline Núcleo de sentido & Resultados das atas \\
\hline $\begin{array}{l}\text { Regulação e controle de } \\
\text { leitos e internações }\end{array}$ & $\begin{array}{l}\text { Esse tema esteve presente em } 42 \% \text { das reuniões, com foco nas } \\
\text { dificuldades de estrutura dos dois hospitais estaduais (geral } \\
\text { e psiquiátrico); nos leitos de UTI para atendimento de casos } \\
\text { de AVC contratualizados com hospital privado, que estavam } \\
\text { ociosos pela chegada de pacientes fora da janela de intervenção } \\
\text { e que passaram a ser mais bem utilizados após as frequentes } \\
\text { orientações da equipe da Central de Regulação de Leitos na } \\
\text { CIR; e no conhecimento e necessidade da adequada utilização } \\
\text { do sistema de regulação hospitalar. Percebeu-se como relevante } \\
\text { a frequente presença dos Coordenadores da Central de leitos } \\
\text { para otimização do funcionamento do Complexo Regulador, } \\
\text { a exemplo do manejo da lista de pacientes "internados" nos } \\
\text { corredores do hospital geral à espera de cirurgias eletivas. } \\
\text { Apesar desses avanços, foram verificados relatos de gestores/ } \\
\text { técnicos municipais quanto a algumas interferências políticas } \\
\text { no processo de regulação de leitos, em detrimento do critério } \\
\text { clínico e do fluxo via Sistema de Informação. }\end{array}$ \\
\hline $\begin{array}{l}\text { Instrumentos para } \\
\text { continuidade do cuidado } \\
\text { entre os níveis de atenção }\end{array}$ & $\begin{array}{l}\text { Não apareceram nas reuniões ou documentos da CIR } \\
\text { indicações de mecanismos para avaliar obstruções na oferta ou } \\
\text { estratégias para fortalecimento de ferramentas de gestão clínica } \\
\text { para melhorar os fluxos (prontuários eletrônicos, protocolos } \\
\text { clínicos regionais, articulação com a APS etc.); }\end{array}$ \\
\hline Transporte sanitário & $\begin{array}{l}\text { Tratamento Fora de Domicílio (TFD) foi um tema recorrente } \\
\text { às reunióes da CIR. Verificou-se que os municípios realizavam } \\
\text { alto investimento em veículos para garantia do transporte dos } \\
\text { pacientes às consultas e procedimentos. }\end{array}$ \\
\hline
\end{tabular}

Um estudo em Florianópolis concluiu que as contribuições do campo logístico podem ser percebidas por meio da implantação de "fluxos de acesso bem delineados e investimentos para a capacitação dos profissionais e para a implantação de uma central de regulação de leitos" (ERDMANN et al., 2013, p. 6).

As reuniōes e atas analisadas da CIR mostram que a busca por constituir redes temáticas e linhas de cuidado foi um forte catalisador para grupos de trabalhos e colaboração sistemática entre gestores. Tais temas, que podem resultar na integração vertical e, portanto, na diminuição da fragmentação por preverem a organização de fluxos e contrafluxos na rede regional, têm sido induzidos pelo Ministério da Saúde e pela SESAB, sobretudo por meio do financiamento das 
políticas de saúde, especialmente a partir da publicação da Portaria no 4.279/2010

(BRASIL, 2010) e Decreto no 7.508/11 (BRASIL, 2011). Para tanto, grupos de trabalho foram ativados, entre 2013 e 2014, como a Rede de Atenção Psicossocial (GT-RAPS), Rede de Atenção às Urgências e Emergências (GT-RUE) e Rede Cegonha (GT-RC), para construção de planos de ação regional.

No cerne do debate intergestores, a Rede de Atenção Psicossocial provocou a reflexão sobre a necessidade de readequar leitos e o atendimento de urgência (inclusive para pessoas com uso abusivo de psicotrópicos) no hospital público estadual Afrânio Peixoto e de implantar serviços de caráter noturno, bem como revelou a dificuldade dos municípios em assumir a sede de CAPS regionais (por insuficiência de profissionais, incipiência no financiamento e impedimentos quanto à Lei de Responsabilidade Fiscal). Se, por um lado, os gestores mostraramse desejosos pela estruturação dessa rede de cuidados, considerando a insuficiência e fragilidade atualmente instaladas e a magnitude do problema do uso abusivo de substâncias, por outro, ficaram reticentes quanto aos mecanismos que garantissem efetivamente a divisão de responsabilidades entre os municípios. Assim, o tema da saúde mental entrou frequentemente nas pautas, com participação ativa de técnicos para esclarecimentos e exposição das diretrizes ministeriais e estaduais.

A integração da Rede de Atenção às Urgências e Emergências (RUE) também ocupou grande parte das reunióes da CIR. Observou-se que tal tema estava mais amadurecido entre os gestores, pois se tratava de processo iniciado desde 2012. Percebe-se que o envolvimento dos gestores municipais no processo de construção das redes tem implicações diretas na sua consolidação e que, a depender de seu protagonismo político, a tensão no processo de construção das redes pode ser maior ou menor (MENDES et al., 2015). Nessa direção, as reuniões pautavam a reorganização dos fluxos e o plano de ação para alocação de serviços em uma rede já em funcionamento, bem como a expansão da cobertura do SAMU regional, inclusive com a aquisição de novas ambulâncias de suporte avançado e motocicletas adaptadas. A implementação da RUE desencadeou a discussão sobre a reorientação na distribuição de salas de estabilização entre os municípios, programação de leitos de retaguarda para demandas de menor urgência em hospitais públicos e privados, implantação de serviço específico para atendimento de AVC com suporte de UTI e construção de Unidades de ProntoAtendimento (UPA). Para essa linha, a SESAB sinalizava o acréscimo de leitos no 
Hospital Regional de Vitória da Conquista, o credenciamento de novos leitos em hospitais privados e a avaliação dos hospitais de pequeno porte da região.

Ainda sobre a RUE, constatou-se que a questão do financiamento compartilhado foi decisiva para o atraso na implementação da rede, visto que alguns municípios contemplados com ambulâncias de suporte avançado do SAMU desistiram de recebê-las em seu território. Além disso, foi discutida a situação das UPAs, com construção muito atrasada em Vitória da Conquista ou pronta, porém sem atendimento, no município de Poçôes. De maneira semelhante, o financiamento, juntamente com a extensão territorial, o despreparo e a rotatividade dos profissionais foram citados como principais dificuldades na implantação da RUE na Macrorregião Norte de Minas Gerais (TORRES; BELISÁRIO; MELO, 2015). Outros desdobramentos foram discutidos na CIR, como a necessidade de fluxo que garantisse o acompanhamento pós-hospitalar ambulatorial com neurologista e outros especialistas na rede, abrindo espaço para percepção de necessidade de ampliar NASFs, bem como propostas de implantar Serviço de Atenção Domiciliar e maior oferta de especialistas no centro de especialidades de Vitória da Conquista, a ser acessado conforme PPI.

A terceira rede temática com frequente debate na CIR foi a Rede Cegonha, esteve estreitamente articulada com a RUE, sobretudo na discussão sobre transporte sanitário em casos de risco para gestante e/ou recém-nascido e intercorrências do parto. A política da Rede Cegonha "procura operacionalizar as políticas já criadas, mas, agora, com um diferencial em relação às anteriores, que é a concretização da articulação dos pontos de atenção numa rede de cuidados integrais" (FERNANDES; VILELA, 2014, p. 4459). No caso estudado, quanto à localização das casas de parto normal (CPN), observou-se intensa discussão entre os gestores, denotação da efetiva participação e implicação no processo de construção da rede, uma vez que exigiam garantias da maternidade de Poçôes no atendimento aos casos referenciados pela $\mathrm{CPN}$, por conta do histórico negativo recente dessa unidade hospitalar. A elaboração do plano da Rede Cegonha também suscitou a discussão da necessidade de qualificação e adensamento dos hospitais de pequeno porte da região (infraestrutura, profissionais, materiais e equipamentos), bem como de garantia dos exames e consultas preconizadas para um pré-natal e puerpério de qualidade e de ampliação da oferta de leitos de gestação de alto risco, UTI e UCI neonatais nos hospitais de referência terciária localizados em Vitória da Conquista. 
Para a articulação dos fluxos na região de saúde, havia em todos os municípios sistemas de acesso regulado para consultas e exames especializados, sendo que, em Vitória da Conquista, localizava-se o sistema de regulação regional para internações hospitalares eletivas e de urgência e emergência. Um estudo em Ribeirão Preto mostrou, ainda, que a existência de um complexo regulador provocou alteraçôes positivas no acesso, no interior da rede de saúde, tanto na assistência ambulatorial quanto na hospitalar (FERREIRA et al., 2010). Dessa forma, o uso de ferramentas clínicas para organização dos fluxos assistenciais pode viabilizar a gestão do cuidado integral em regiōes de saúde (SANTOS; GIOVANELLA, 2016a).

$\mathrm{Na}$ região pesquisada, tais mecanismos regulatórios estiveram sempre presentes como pauta nas reuniôes da CIR, ou mesmo oriundos de debates internos, e ocuparam parte significativa dos debates. Destacou-se a frequente participação de profissionais da Central de Regulação Regional de Leitos na discussão dos entraves e na articulação de soluções junto aos gestores, ora apresentando a organização e funcionamento da central de regulação, ora conclamando os gestores para atualizarem os cadastros de estabelecimentos e profissionais da região no Sistema Nacional de Cadastro de Estabelecimentos de Saúde (SCNES), que permitam conhecer a capacidade instalada e a oferta potencial dos leitos em cada território da região para o planejamento e a utilização dos serviços no local mais apropriado e oportuno.

Além disso, recomendava-se o cadastramento no SISREG III e qualificação de técnicos nos municípios para lidar adequadamente com o sistema de informação, buscando fluidez na regulação. É importante salientar que uma simples presença de um complexo regulador não faz com que a assistência seja ofertada de maneira equânime e integral. Nesse sentido, um estudo sobre o desenvolvimento da regulação assistencial na Grande Recife evidenciou que o complexo regulador pouco fez para aumentar a oferta de serviços especializados municipais; o acesso propiciado pela regulação "restringiu-se à 'adequação' da demanda à oferta da rede complementar SUS/Recife” (ALBUQUERQUE et al., 2013, p. 223). Percebese, portanto, que, sem alterar o modelo de atenção centrado no procedimento médico, e sem aumentar a resolubilidade da APS por meio da coordenação do cuidado (SANTOS; GIOVANELLA, 2016b), pouco se avança na organização da rede de atenção. 
Observou-se que a presença de técnico da regulação de leitos qualificou o debate entre gestores na CIR. Constataram-se denúncias de secretários de saúde sobre interferências políticas no fluxo de internamento em detrimento de critérios da regulação oficial; por sua vez, houve a apresentação, pela central de regulação de leitos, de lista de municípios que foram considerados "campeões" de encaminhamentos fora do protocolo do SISREG III, comprometendo a vida dos pacientes transferidos, algumas vezes, sem a devida estabilização clínica do caso. Tais debates, explicitados em reunião da CIR, colocavam frente a frente gestores e outros atores, possibilitando a definição compartilhada de medidas para solução de problemas que afetavam a todos.

Dentre os sistemas regulatórios, a discussão sobre marcação de exames esteve mais associada ao financiamento e à desatualização da PPI do que especificamente às centrais de marcação de consultas ou propriamente à regulação dos fluxos. Ressalta-se, por conseguinte, que, apesar dos recorrentes embates por ampliação de oferta de vagas nas diferentes especialidades, não apareceram nas reuniōes ou documentos da CIR indicações de mecanismos para avaliação de tais obstruções na oferta e/ou estratégias para fortalecimento de ferramentas de gestão clínica para melhorar os fluxos (prontuários eletrônicos, protocolos clínicos regionais, articulação com a APS etc.).

Por outro lado, a CIR parece expandir o diálogo com novos atores na perspectiva de ampliar a governança regional. Em uma das reuniões, por exemplo, houve a presença de promotora do Ministério Público Estadual para manifestar que aquele órgão ocupa-se, também, da situação dos serviços de saúde da região, especialmente do Hospital Regional de Vitória da Conquista e, igualmente, alertar os gestores para as suas responsabilidades sanitárias perante a população.

Por fim, para acesso aos diferentes serviços de saúde ofertados fora do município de origem, os gestores necessitam de soluções logísticas para viabilizar o transporte sanitário e meio de subsistência para os usuários e, muitas vezes, para seus acompanhantes. Para essa finalidade, está previsto o programa de Tratamento Fora do Domicílio (TFD). O TFD consiste em fornecimento de passagens, ajuda de custo para alimentação e pernoite para viabilizar o atendimento especializado ao usuário do SUS (BAHIA, 2012). Não obstante, foi um tema recorrente nas reunióes da CIR, especialmente para sinalizar que os municípios têm despendido muito mais recurso que o disponibilizado pelo TFD. Como desdobramento 
desse problema, constataram-se, nas reuniōes e documentos da CIR, momentos

de esclarecimento de técnicos da SESAB sobre o uso inadequado do TFD.

\section{Considerações finais}

A despeito de sua complexidade, condicionada por diferentes fatores, como as grandes desigualdades e diversidades regionais no país, o processo de regionalização pode interferir de forma positiva na universalidade do acesso à saúde, ao permitir ou mesmo exigir o planejamento e a organização das redes de acordo com as necessidades locorregionais (VIANA et al., 2015). Nesse sentido, a CIR representa um fórum potencial de debates e construção de estratégias de governança regional. No caso estudado, desempenhou um papel de espelho das situações e problemáticas expressas no território regional.

Dentre os assuntos pertinentes à atenção secundária, tiveram destaque, especialmente o planejamento e regulação de seus pontos de atenção. Conforme destacam Solla e Chioro (2012), a configuração de uma rede regionalizada é essencial para garantir uma atenção especializada, e a APS tem redefinido os papéis da atenção secundária e terciária. A despeito dessa lógica, o estudo mostrou a quase ausência da temática da APS nas discussões da CIR, sem considerar sua importância para a configuração de uma rede regionalizada. Esses achados convergem com outros estudos sobre temáticas prevalentes nas discussōes da CIR (SANTOS; ALMEIDA, 2015) e sinalizam certa percepção restrita sobre as Redes da Atenção à Saúde, que se circunscreve à garantia da oferta de atenção especializada e hospitalar.

Outro achado que merece destaque refere-se à busca de soluções municipais para problemas claramente regionais. Conforme apresentado, alguns municípios, em dissonância com os princípios de cooperação necessários à construção do espaço regional, optam pela compra direta de serviços de prestadores privados, muitas vezes, mediada pela ação de atravessadores e pela sobreposição de fluxos, minando a solidariedade e comprometendo a economia de escala, tão necessária à garantia da qualidade da atenção e melhores custos. Destaca-se que esse é um desafio enfrentado na maioria dos sistemas de saúde americanos e que, embora a fragmentação e a duplicação de serviços tenham sido foco de reformas no setor saúde, poucos foram os casos exitosos (SOLLA; CHIORO, 2012). 
É justificável, no entanto, a premência imposta pela tentativa de garantir atenção especializada, reconhecidamente um dos maiores pontos de estrangulamento do SUS, tradicionalmente organizada e financiada pela lógica da oferta e não das necessidades de saúde da população, agravada pela defasagem da tabela SUS.

Um ponto positivo refere-se ao amadurecimento e à qualificação do quadro de gestores a partir da participação na CIR e em seus grupos de trabalho, conforme observado na CIR de Vitória da Conquista. Nesse sentido, o desenvolvimento de capacidades gerenciais e administrativas é um fator fundamental para o desempenho de funções de regulação, controle e avaliação capazes de instituir novas relações entre público e privado em prol do interesse público e das necessidades coletivas.

\section{Referências}

ALBUQUERQUE, M. S. V. et al. Regulação Assistencial no Recife: possibilidades e limites na promoção do acesso. Saúde e Sociedade, São Paulo, v. 22, n. 1, p. 223-236, 2013.

ALMEIDA, P. F.; SANTOS, A. M. Diálogos em busca de coordenação do cuidado: linha de chegada ou novo itinerário? In: ALMEIDA, P. F. de; SANTOS, A. M. dos; SOUZA, M. K. B. de (Org.). Atenção primária à saúde na coordenação do cuidado em regiōes de saúde. Salvador: Edufba, 2015. p. 277-303.

ASSIS, M. M. A.; JESUS, W. L. A. Acesso aos serviços de saúde: abordagens, conceitos, políticas e modelo de análise. Ciência \& Saúde Coletiva. Rio de Janeiro, v. 17, n. 11, p. 28652875, 2012.

BAHIA. Plano Diretor de Regionalização: regiōes de assistência em saúde. Disponível em: $<$ http://wwwl.saude.ba.gov.br/mapa_bahia/\#PDR>. Acesso em: 6 out. 2015.

BAHIA. Regiōes de saúde do estado da Bahia. Disponível em: < http://www1.saude.ba.gov.br/ mapa_bahia/docs/PDR_POP2012_atualizado10-07-2013.pdf >. Acesso em: 7 out. 2015.

BAHIA. Manual de normatização do Tratamento Fora do Domicílio estado da Babia. SESAB: Salvador, 2012.

BAHIA, L. A privatização no sistema de saúde brasileiro nos anos 2000: tendência e justificação. In: SANTOS, N.R.; AMARANTE, P.D.C. (Org.). Gestão pública e relação público privado na saúde. Rio de Janeiro: Cebes, 2010. p. 115-128.

BRASIL. Decreto no 7.508, de 28 de junho de 2011. Dispõe sobre a organização do Sistema Único de Saúde - SUS, o planejamento da saúde, a assistência à saúde e a articulação interfederativa e dá outras providências. Diário Oficial da Uniāo. Brasília, DF, 29 jun. 2011. BRASIL. Diretrizes Operacionais: Pactos pela Vida, em Defesa do SUS e de Gestão. Brasília: Ministério da Saúde, 2006. 75p. 
BRASIL. Portaria no 4.279, de 30 de dezembro de 2010. Estabelece diretrizes para a organização da Rede de Atenção à Saúde no âmbito do Sistema Único de Saúde (SUS). Diário Oficial da União. Brasília, DF, 2010.

CAMPOS, G. W. S. Cogestão e neoartesanato: elementos conceituais para repensar o trabalho em saúde combinando responsabilidade e autonomia. Ciência \& Saúde Coletiva, Rio de Janeiro, v. 15, n. 5, p. 2337-2344, 2010.

DUARTE, C. M. R. et al. Regionalização e desenvolvimento humano: uma proposta de tipologia de regiões de saúde no Brasil. Cadernos de Saúde Pública, Rio de Janeiro, v. 31, n. 6, p. 1163-1174, 2015.

DUBEUX, L. S.; CARVALHO, E. F. de. Caracterização da oferta de serviços especializados em hospitais de referência regional: uma contribuição para a regionalização da assistência à saúde no SUS. Rev. Bras. Saúde Matern. Infant., Recife, v. 9, n. 4, p. 467-476, 2009.

ERDMANN, A. L. et al. A atenção secundária em saúde: melhores práticas na rede de serviços. Rev. Latino-Am. Enfermagem, Ribeirão Preto, v. 21, n. Spec., [08 telas], 2013.

FERNANDES, R. Z. S.; VILELA, M. F. G. Estratégias de integração das práticas assistenciais de saúde e de vigilância sanitária no contexto de implementação da Rede Cegonha. Ciência \& Saúde Coletiva. Rio de Janeiro, v. 19, n. 11, p. 4457-4466, 2014.

FERREIRA, J. B. B. et al. O complexo regulador da assistência à saúde na perspectiva de seus sujeitos operadores. Interface, Botucatu, v. 14, n. 33, p. 345-358, 2010.

FLICK, U. Qualidade na pesquisa qualitativa. Porto Alegre: Bookman, 2009. 150p.

GAWRYSZEWSKI, A. R. B.; OLIVEIRA, D. C.; GOMES, A. M. T. Acesso ao SUS: representações e práticas de profissionais desenvolvidas nas Centrais de Regulação. Physis: Revista de Saúde Coletiva. Rio de Janeiro, v. 22, n. 1, p. 119-140, 2012.

LIMA, L. D. de et al. Descentralização e regionalização: dinâmica e condicionantes da implantação do Pacto pela Saúde no Brasil. Physis: Revista de Saúde Coletiva. Rio de Janeiro, v. 17, n. 7, p. 1903-1914, 2012.

MACHADO, J. A. Ação coletiva e provisão de bens públicos por meio de formas consorciadas entre governos locais: os consórcios intermunicipais de saúde no Brasil. Teoria e Sociedade, Belo Horizonte, v. 18, n. 1, p. 144-165, 2010.

MEDEIROS, C. R. G. Redes de atenção em saúde: o dilema dos pequenos municípios. 2013. 201 p. Tese (Doutorado em Enfermagem) - Escola de Enfermagem, Universidade Federal do Rio Grande do Sul, Porto Alegre, 2013.

MENDES, A. et al. O processo de construção da gestão regional da saúde no estado de São Paulo: subsídios para a análise. Saúde e Sociedade, São Paulo, v. 24, n. 2, p. 423-437, 2015.

MENDES, E. V. As redes de atenção à saúde. Ciência \& Saúde Coletiva, Rio de Janeiro, v. 15, n. 5, p. 2297-2305, 2010. 
MINAYO, M. C. S. O desafio do conhecimento: pesquisa qualitativa em saúde. São Paulo: Hucitec, 2010. 407p.

OCKÉ-REIS, C. O. SUS: o desafio de ser único. In: SANTOS, N. R. dos; AMARANTE, P. D. C. (Org.). Gestão pública e relação público privado na saúde. Rio de Janeiro: Cebes, 2010. p. 101-114.

OPAS. Organización Panamericana de la Salud. Redes Integradas de Servicios de Salud Basadas en la Atención Primaria de Salud. Washington, D.C.: OPS, 2009.

SANTOS, A. M.; GIOVANELLA, L. Governança regional: estratégias e disputas para gestão em saúde. Rev. Saúde Pública, São Paulo, v. 48, n. 4, p. 622-631, 2014.

- Gestão do cuidado integral: estudo de caso em região de saúde. Cad. Saúde

Pública, Rio de Janeiro, v. 32, n. 3, p. e0017-2214, 2016 a.

Estratégia Saúde da Família na coordenação do cuidado em região de saúde na Bahia. Rev. Saúde em Debate, Rio de Janeiro, v. 40, n. 108, p. 48-63, 2016 b.

SANTOS, L.; ANDRADE, L. O. M. de. Redes interfederativas de saúde: um desafio para o SUS nos seus vinte anos. Ciência \& Saúde Coletiva, Rio de Janeiro, v. 16, n. 3, p. 16711680, 2011.

SANTOS, L.; CAMPOS, G. W. S. SUS Brazil: The health region as a way forward. Saúde e Sociedade, São Paulo, v. 24, n. 2, p. 438-446, 2015.

SERRA, C. G.; RODRIGUES, P. H. A. Avaliação da referência e contrarreferência no Programa Saúde da Família na Região Metropolitana do Rio de Janeiro (RJ, Brasil). Ciência \& Saúde Coletiva, Rio de Janeiro, v. 15, supl. 3, p. 3579-3586, 2010.

SILVA, E. C. da; GOMES, M. H. A. Regionalização da saúde na região do Grande ABC: os interesses em disputa. Saúde e Sociedade, São Paulo, v. 23, n. 4, p. 1383-1396, 2014.

SILVA JUNIOR, A. G. da et al. Regionalização, integralidade e produção do cuidado no contexto da Estratégia Saúde da Família: pontos para o debate. In: ALMEIDA, P. F. de; SANTOS, A. M. dos; SOUZA, M. K. B. de (Org.). Atenção primária à saúde na coordenação do cuidado em regióes de saúde. Salvador: Edufba, 2015. p. 65-88.

SOLLA, J.; CHIORO, A. Atenção ambulatorial especializada. In: GIOVANELLA, L. et al. (Org.). Políticas e Sistema de Saúde no Brasil. Rio de Janeiro: Editora Fiocruz, 2012. p. 547-576.

SOUSA, F. O. S. et al. Do normativa à realidade do Sistema Único de Saúde: revelando barreiras de acesso na rede de cuidados assistenciais. Ciência \& Saúde Coletiva, Rio de Janeiro, v. 19, n. 4, p. 1283-1293, 2014.

SPEDO, S. M.; PINTO, N. R. S.; TANAKA, O. Y. O difícil acesso a serviços de média complexidade do SUS: o caso da cidade de São Paulo, Brasil. Physis: Revista de Saúde Coletiva. Rio de Janeiro, v. 20, n. 3, p. 953-972, 2010. 
TORRES, S. F. S.; BELISÁRIO, S. A.; MELO, E. M. A Rede de Urgência e Emergência da Macrorregião Norte de Minas Gerais: um estudo de caso. Saúde e Sociedade, São Paulo, v. 24, n. 1, p. 361-373, 2015.

VIANA, A. L. A.; LIMA, L. D. de; FERREIRA, M. P. Condicionantes estruturais da regionalização na saúde: tipologia dos colegiados de gestão regional. Ciência \& Saúde Coletiva, Rio de Janeiro, v. 15, n. 5, p. 2317-2316, 2010.

VIANA, A. L. A. et al. Tipologia das regiōes de saúde: condicionantes estruturais para a regionalização no Brasil. Saúde e Sociedade. São Paulo, v. 24, n. 2, p. 413-422, 2015.

VIANNA, R. P. Colegiados de gestão regional no estado do Rio de Janeiro: atores, estratégias e negociação intergovernamental. 2012. 155 p. Dissertação (Mestrado em Ciências em Saúde Pública) - Escola Nacional de Saúde Pública Sergio Arouca, Rio de Janeiro, 2012.

VICTORA, C. G. et al. Condições de saúde e inovações nas políticas de saúde no Brasil: o caminho a percorrer. The Lancet. Reino Unido, v. 377, n. 9782, p. 2042-2053, 2011.

VIDOR, A. C.; FISHER, P. D.; BORDIN, R. Utilização dos sistemas de informação em saúde em municípios gaúchos de pequeno porte. Rev. Saúde Pública. São Paulo, v. 45, n. 1, p. 24-30, 2011.

YIN, R. K. Estudo de caso: planejamento e métodos. Porto Alegre: Bookman, 2005.

\section{Nota}

${ }^{1}$ R. M. Silveira Filho participou da concepção do projeto, coletou e analisou os dados, fez as observaçôes nas reuniōes da CIR de Vitória da Conquista, redigiu o artigo e aprovou a versão final. A. M. dos Santos participou da concepção do projeto, redação do artigo e aprovação da versão final. J. A. Carvalho prestou consultoria a respeito do objeto de estudo e realizou análise de dados; participou da revisão final. P. F. de Almeida participou da análise e revisão da versão final do artigo. Os autores declaram não haver conflito de interesses na presente pesquisa e que a mesma foi financiada pela Universidade Federal da Bahia (UFBA), por meio do Programa de Apoio a Pesquisadores Emergentes da UFBA (PRODOC/UFBA). 
Measures by a Regional Inter-managerial

Commission to regulate specialized services in Brazil's National Health System

Fragmentation of care and the difficulty of offering comprehensive care pose the need to establish a cohesive regional health territory with cooperation among municipalities. As a locus of regional governance, the health authorities' Regional Inter-managerial Commission (Comissão Intergestores Regional, CIR) is a space for concertation and cooperation to strengthen the health region. This paper aims to identify how regulation of specialized health services is addressed in CIR discussions and what the chief recommendations are. A qualitative study was conducted from 2013 to 2015, on the basis of a documentary review, by analysis of the minutes and monthly observation of CIR meetings, which involved 19 municipalities. The results indicated that, despite diversified agendas, the focus was hospital care. Regulatory processes considered were restricted to creating regional flows to hospital care. A concern was observed with the permanent review of the funding ceiling for the agreed integrated programme (Programação Pactuada e Integrada, PPI) and with the indicators of the system for agreeing health guidelines, goals, targets and indicators (Sistema de Pactuação de Diretrizes, Objetivos, Metas e Indicadores de Saude, SISPACTO). In the case studied, the CIR was a powerful space for regional governance. The meetings highlighted the common difficulties and the managers' strategies for surmounting problems in supply and access to specialized services among municipalities.

> Key words: regional health planning; health services accessibility; health services administration; secondary health; health services coverage. 